\title{
Influence of Spatial Relationships between Key Strata on the Height of Mining-Induced Fracture Zone: A Case Study of Thick Coal Seam Mining
}

\author{
Peng Li ${ }^{1}$, Xufeng Wang ${ }^{1,2,3, *}$, Wenhao Cao ${ }^{1}$, Dongsheng Zhang ${ }^{1,4}$, Dongdong Qin ${ }^{1}$ and \\ Hongzhi Wang ${ }^{1}$ \\ 1 School of Mines, China University of Mining \& Technology, Xuzhou 221116, China; \\ lipeng@cumt.edu.cn (P.L.); caowenhao0325@cumt.edu.cn (W.C.); zds@cumt.edu.cn (D.Z.); \\ qindongdong@cumt.edu.cn (D.Q.); cumterwhz@cumt.edu.cn (H.W.) \\ 2 The Jiangsu Laboratory of Mining-Induced Seismicity Monitoring, China University of Mining \& \\ Technology, Xuzhou 221116, China \\ 3 Key Laboratory of Deep Coal Resource Mining, China University of Mining \& Technology, \\ Xuzhou 221116, China \\ 4 State Key Laboratory of Coal Resources and Safe Mining, China University of Mining \& Technology, \\ Xuzhou 221116, China \\ * Correspondence: wangxufeng@cumt.edu.cn; Tel.: +86-159-5067-2601
}

Received: 14 December 2017; Accepted: 2 January 2018; Published: 3 January 2018

\begin{abstract}
The behavior of the overburden of working face 20104 at the Wangjialing coal mine was investigated using borehole imaging. The measured height of the conductive fracture zone (CFZ) in the overburden, $148 \mathrm{~m}$, is significantly different from the height that is predicted by an empirical formula. The spatial relationships between key strata (KS) required for their fracturing and their influence on the CFZ's height were analyzed. The results demonstrate that the spatial relationships between adjacent KS are a major factor behind the abnormal increase in the height of CFZ relative to the coal seam. The height of linkage (HoL) between KS was introduced and an equation for calculating this height was proposed. The study found that the fracturing of a KS could induce fracturing of the adjacent KS above it if their height difference was smaller than the HoL between them. Otherwise, the fractures resulting from the lower KS would terminate at the bottom of the higher KS. When the location of a high KS satisfies certain requirement, the spatial linkage between adjacent KS will allow for the conductive fractures arising in a lower KS to propagate through the high KS as well as the strata controlled by it, thus increasing the height of CFZ in overburden.
\end{abstract}

Keywords: field measurements; thick seam mining; mining-induced fractures; key strata

\section{Introduction}

The pattern of evolution of mining-induced fractures in overburden is a theoretical basis for preventing water inflow, fire and gas-related disasters, and other mine disasters. Meanwhile, it also provides useful guidance on how to protect regional water resources, especially in mine areas with fragile ecology [1-4]. Extensive research has looked at the height of mining-induced conductive fracture zone (CFZ) for different conditions using various detection techniques and research methods, and provided important guidance and support for environmental mining. The findings of relevant research are summarized below:

(1) Some researchers have investigated characteristics of growth of mining-induced fractures in overburden under different conditions. For instance, Zhang et al. investigated the height of fracture zone in overburden in studies focusing on aquifer protection during longwall mining of shallow coal seams [5,6]. Ju and Shi, et al., respectively, studied the characteristics of mining-induced surface 
subsidence and fractures in overburden above an ultra thick coal seam $[7,8]$. Their results can be used as reference for safe mining of ultra thick seams occurring in western China. Wang and Wang et al., respectively, analyzed the evolution of CFZ and slope movement induced by coal mining under gullies and provided corresponding control techniques $[9,10]$. Zhang et al. analyzed the factors affecting the height of CFZ in overburden in solid backfill mining [11]. A series of studies by V.Palchik have investigated the formation of fractured zone due to mining under weak rock mass or weathered overburden and the factors influencing it [12-14]. These findings on fractures in overburden created by mining under different conditions provide effective support for ensuring mine safety. Given the diverse geological conditions of coal mines, however, further research is needed to deepen and extend existing knowledge about mining-induced fractures in overburden.

(2) Recent studies have employed a variety of techniques and equipment to detect mining-induced fractures in overburden and produced good results. For example, Cheng et al. investigated the overburden movement induced by coal mining using microseismic monitoring and developed a method for zoning overburden in a vertical direction [15]. Xiong and Wang et al. studied mininginduced fractures in overburden through field investigation combined with borehole imaging, which allows for the visualization of the fracture development process $[16,17]$. Some scholars have used endoscopic observations of fractures to describe the quality of rocks, and studied the rock mass stratification [18-20]. Zhang et al. have proposed the use of on-site radon detection to monitor the evolution of mining-induced fractures in overburden and demonstrated its feasibility through field experiments [21,22]. Applications of these detection techniques and equipment make the analysis of mining-induced CFZ's height easier and more accurate.

(3) Empirical formulas for predicting the CFZ's height have been derived from statistics and used as a tool to ensure safe coal mining. For some special geological conditions, however, the predictions by these empirical formulas are inconsistent with the actual heights of the CFZ, due to limitations of early production technology and statistical samples. Some scholars have used the theory of key strata to explain this discrepancy. By analog simulation experiments and field measurements, $\mathrm{Xu}$ and Miao et al. found that the height of CFZ depends largely on whether the primary key stratum (PKS) fractures or not, and that the location of PKS is a major factor influencing the CFZ's height [23,24]. These findings enrich the theory of key strata and extend its applications, but no one has provided a detailed analysis of the influence of spatial relationships between KS on the CFZ's height in the cases where there are multiple KS in overlying strata.

In this study, the evolution of mining-induced fractures in overburden above a thick coal seam and the fracturing processes experienced by the key strata were observed through borehole imaging. Based on the spatial relationships between KS required for fracturing them, a set of models were developed to explain the reason behind the large height of the CFZ induced by thick seam mining. These models provide a new approach to predicting the CFZ's height from the locations of KS.

\section{Development of Fractures in Overburden Induced by Thick Seam Mining}

\subsection{Geological Conditions}

Working face 20104 at the Wangjialing coal mine is the first coal face in the 2\# coal seam, from which the coal is extracted by fully-mechanized top-coal caving. It is $230 \mathrm{~m}$ wide and $1214 \mathrm{~m}$ long in its advance direction. The surface elevation ranges from $+803 \mathrm{~m}$ to $+953.9 \mathrm{~m}$ asl, and the elevation of the $2 \#$ coal seam is between $+579.3 \mathrm{~m}$ and $+614.4 \mathrm{~m}$ asl. This seam has relatively uniform properties and distribution across this mine. It dips at $2^{\circ}$ to $4^{\circ}$, and is $5.91 \mathrm{~m}$ to $7.77 \mathrm{~m}$ thick, with an average thickness of about $6.84 \mathrm{~m}$. The mining height is $6.2 \mathrm{~m}$. The layout of working face 20104 is shown in Figure 1. 


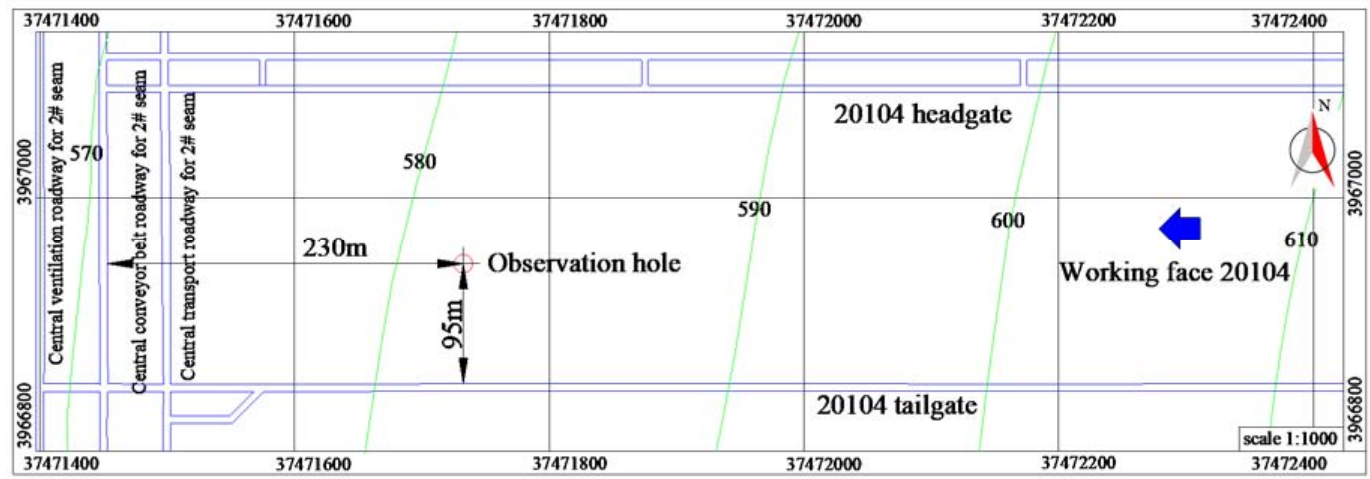

Figure 1. Layout of working face 20104.

\subsection{Field Measurements of the Height of CFZ}

An observation hole was made into the surface above working face 20104 for observing the height of the CFZ by borehole imaging (Figure 2). The observation hole was $230 \mathrm{~m}$ from the central transport roadway for 2\# seam and $95 \mathrm{~m}$ from 20104 tailgate, as shown in Figure 1. This hole is about $250 \mathrm{~m}$ deep and its mouth at the surface has an elevation of $+829.9 \mathrm{~m}$. The positions of key strata in the overburden were identified using KSPB, software for locating key strata (the computational method of this software is based on the key Strata theory and the identification of KS) $[25,26]$. It was found that there are four key strata above working face 20104, including a PKS and three secondary key strata (SKS) (Figure 3).

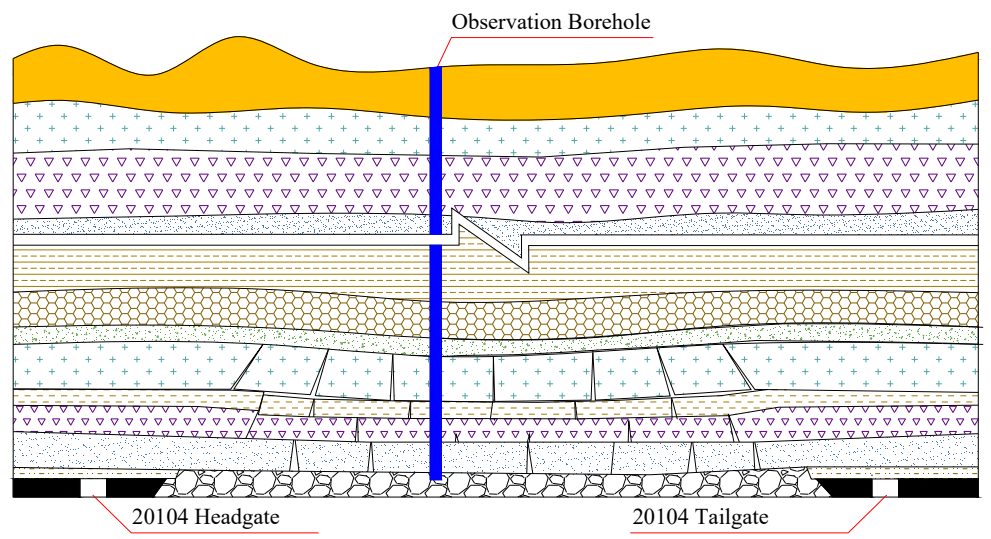

Figure 2. Schematic of the observation borehole and the section across working face 20104.

A TYGD10 borehole camera was placed into the observation hole to observe the deformation of the hole wall. The images it produced are presented in Figure 4 . When the face was about $21 \mathrm{~m}$ in front of the hole, the wall rock at a depth of $226.6 \mathrm{~m}$ from the mouth (SKS 1) caved in and blocked the hole (Figure 4a). At this point, the height of the caved zone was $17.26 \mathrm{~m}$. When the face was $32 \mathrm{~m}$ ahead of the hole, the wall rock caved in at a depth of $220 \mathrm{~m}$ and the height of the caved zone reached $23.96 \mathrm{~m}$ (Figure $4 \mathrm{~b}$ ). Later, the vertical extent of the caved zone did not increase significantly and the strata above it showed noticeable fractures. Bed separations occurred at positions that were slightly lower than SKS 2. As the working face further advanced, bed separations, vertical fractures and horizontal fractures continued growing upward. As the face reached $78 \mathrm{~m}$ in front of the observation hole, SKS 2 failed due to the occurrence of bed separations and vertical fractures, and the hole wall deformed significantly (Figure 4c,d). When the distance between the hole and the face increased to about $100 \mathrm{~m}$, a vertical fracture was observed at a depth of $103.5 \mathrm{~m}$ (Figure 4e), and the wall rocks ranging from $103.5 \mathrm{~m}$ to $125 \mathrm{~m}$ in depth were fractured to a much lesser extent. At this point, the height of the CFZ 
was $140.46 \mathrm{~m}$. As the distance further increased, the height of the CFZ did not change obviously and ultimately reached its maximum, $148 \mathrm{~m}$, a level close to the bottom of SKS 3.

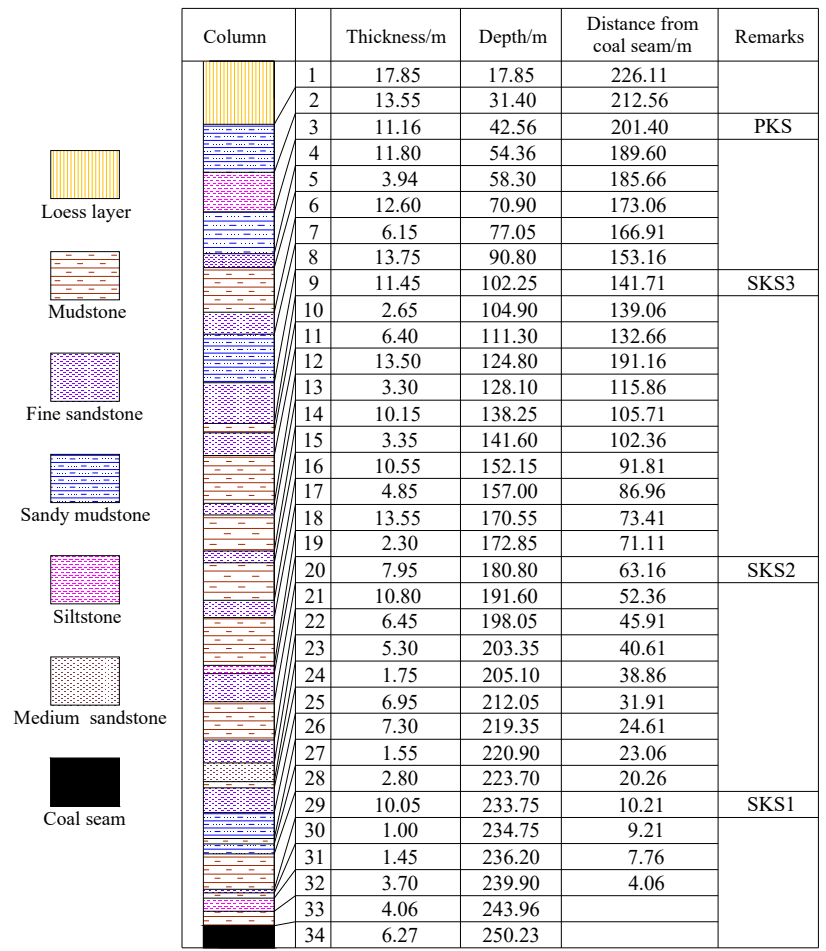

Figure 3. Stratigraphic column of working face 20104.

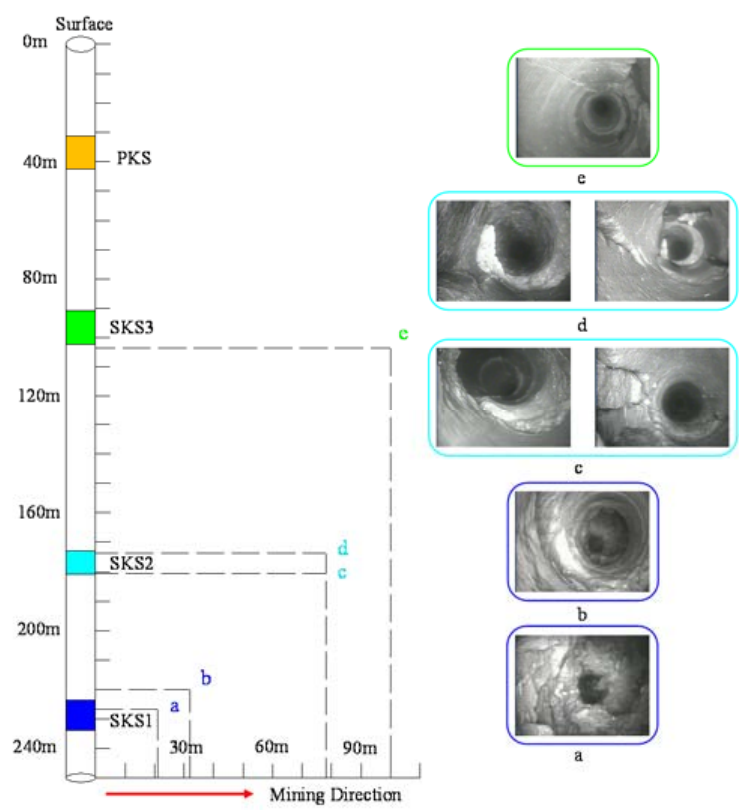

Figure 4. Borehole images: (a) Hole bottom blocked by cave-in of SKS 1; (b) upward development of the caved zone and fractures; (c) bed separations and fractures at the bottom of SKS 2; (d) bed separations and fractures at the top of SKS 2; and, (e) micro-fractures near the bottom of SKS 3.

The field measurements reveal that the CFZ in the overburden of working face 20104 at the Wangjialing coal mine was about $148 \mathrm{~m}$ high, 23.87 times greater than the mining height. As Figure 5 
shows, the CFZ can be divided into two zones: a $23.96 \mathrm{~m}$ high caved zone ( 3.86 times the mining height) and a $124.04 \mathrm{~m}$ high fractured zone (20.01 times the mining height). It is worth noting that the measured height of the CFZ at working face 20105 ranged from $141.6 \mathrm{~m}$ to $163.1 \mathrm{~m}$, or 22.84 to 26.31 times the mining height [17], which is similar to that measured at working face 20104. Later, the empirical formula shown in Equation (1) was used to calculate the CFZ's height for the conditions of working face 20104:

$$
H_{d}=\frac{100 \sum M}{1.2 \sum M+2.0} \pm 8.9=\frac{100 \times 6.2}{1.2 \times 6.2+2.0} \pm 8.9=65.68 \pm 8.9 m
$$

where $M$ is the mining height, set at $6.2 \mathrm{~m}$. At working face 20104, the cutting height is $3 \mathrm{~m}$ and caving height is $3.2 \mathrm{~m}$.

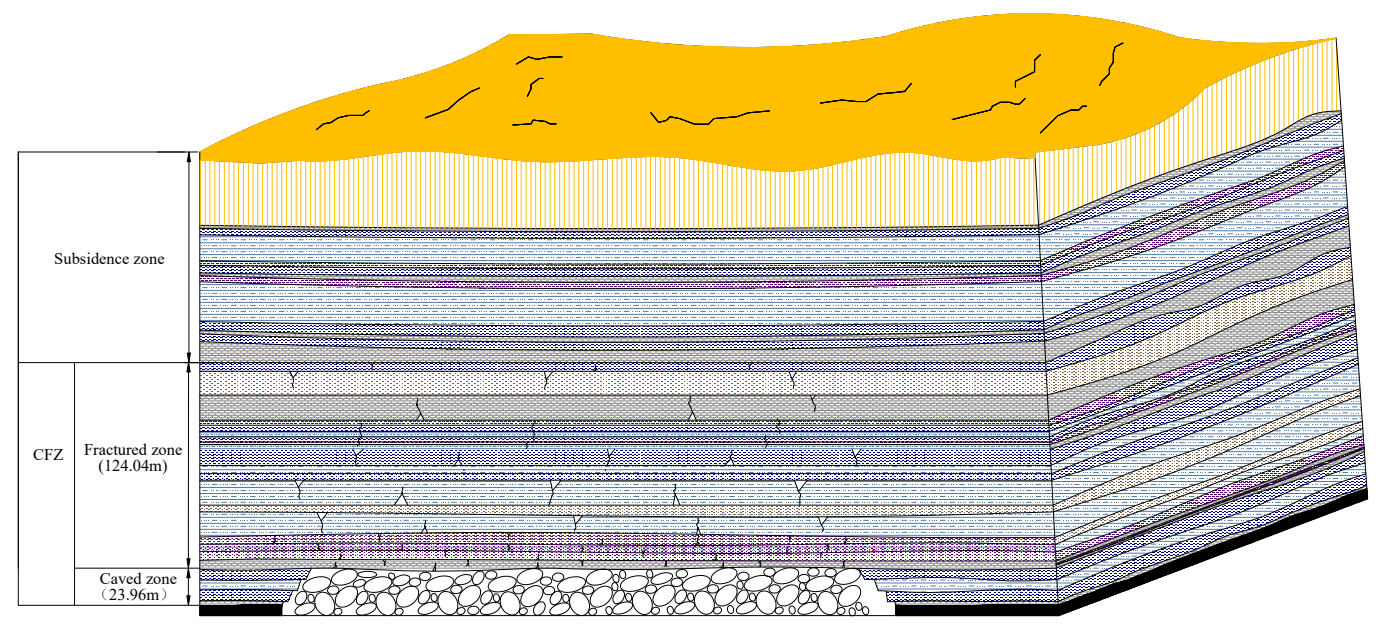

Figure 5. Measured heights of the three zones in the overburden.

A comparison between the measured height of the mining-induced CFZ and the height calculated by Equation (1), for such conditions shows that there was a significant, abnormal increase in the height of the CFZ at working face 20104.

\section{The Mechanism by Which the KS Influenced the CFZ's Height}

\subsection{Influence of KS on the CFZ's Height}

As the immediate roof collapsed into the goaf during mining, the span of exposed KS in the advance direction of the face gradually increased. Therefore, an unfractured KS can be simplified to a clamped-clamped beam structure that is inserted into the surrounding rocks at both ends. Figure 6 illustrates the state of unfractured SKS 1 exposed by the collapse of the immediate roof of working face 20104 and the corresponding clamped-clamped beam model is shown in Figure 7.

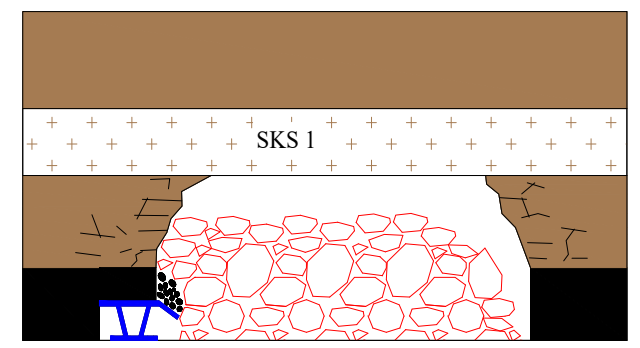

Figure 6. State of SKS 1 after collapse of the immediate roof. 


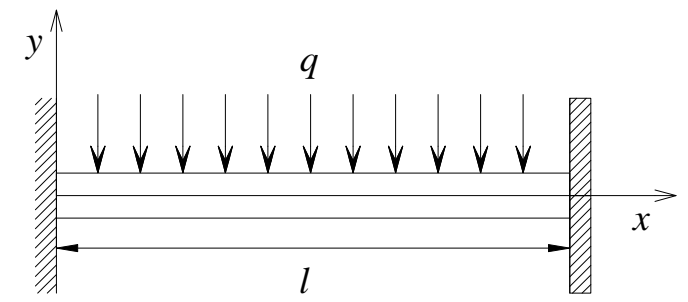

Figure 7. Clamped-clamped beam model for SKS 1.

As exposed KS reaches its limit span, the rock beam will fracture and the corresponding maximum deflection is given by:

$$
w_{\max }=\frac{h R_{T}^{2}}{8 E q}
$$

where $h$ is the thickness of this KS; $q$ is the load acting on it; $R_{T}$ is the KS' tensile strength; and, $E$ is its elastic modulus.

Table 1 shows that the maximum deflections predicted by Equation (2) for the KS in the overburden of working face 20104 were all less than $6 \mathrm{~mm}$. Since the face was scheduled to advance a long distance of $1214 \mathrm{~m}$ continuously, it is reasonable to infer that the KS at this face were bound to fracture when their spans reached corresponding limits, as long as there was a free space below the KS.

Table 1. Maximum deflections of the KS at working face 20104.

\begin{tabular}{cccccc}
\hline KS No. & Rock Type & Thickness $(\mathbf{m})$ & Tensile Strength $(\mathbf{M P a})$ & Elastic Modulus (GPa) & Wmax (mm) \\
\hline SKS 1 & Mudstone & 10.05 & 2.2 & 17.0 & 5.9 \\
SKS 2 & Fine sandstone & 7.95 & 6.0 & 45.6 & 2.6 \\
SKS 3 & Fine sandstone & 11.45 & 6.0 & 45.6 & 3.1 \\
PKS & Siltstone & 11.16 & 5.2 & 40.0 & 1.4 \\
\hline
\end{tabular}

In previous analyses of the CFZ's height based on the theory of key strata, it is generally believed that after a KS fractures, the strata it controls will fracture in response and be cut through by conductive fractures. After coal is extracted from a thick coal seam, the roof is then allowed to fall into a relatively large space. Despite that the bulking of caved roof strata will reduce the size of free space below $\mathrm{KS}$, the conductive fractures will run through the adjacent KS above it if the condition for fracturing the higher KS is satisfied. As a result, the CFZ will increase in height. This indicates that the spatial relationships between adjacent KS are a key factor influencing the height of CFZ induced by mining.

\subsection{Spatial Relationships between KS Required for Their Fracturing}

The height of the CFZ measured at working face 20104 was about $148 \mathrm{~m}$. Fractures in this zone propagated upward through SKS 1 and SKS 2 and then terminated at the lower boundary of SKS 3. The spatial relationships between adjacent KS required for fracturing them were analyzed in terms of whether there was free space between the KS. Let $H_{i-1, i}^{\prime}$ denote the height difference between KS $i-1$ and KS $i$ (i.e., the actual thickness of strata lying between them), $k_{i-1, i}$ denote the bulking factor of strata between the two KS, and $h_{i}$ be the thickness of KS $i, m$ be the height of mining. Let $H_{0,1}^{\prime}$ and $k_{0,1}$ denote the actual thickness and bulking factor, respectively, of the strata between the coal seam and KS 1.

Suppose that KS 1 fractures. To allow KS 2 to reach its limit span and fracture after KS 1 fractures, the height difference between the two KS, denoted $H_{1,2}$, should satisfy the condition given by Formula (3).

Similarly, for the fracturing of KS 2 to induce fracturing of the third KS, the height difference between them, as denoted $H_{2,3}$, must satisfy the condition given by Formula (4). 
Then the fracturing of KS $n$ can cause KS $n+1$ to fracture if their height difference, $H_{n, n+1}$, satisfies the condition given by Formula (5).

$$
\begin{gathered}
m-H_{0,1}^{\prime}\left(k_{0,1}-1\right)-\left(h_{1}+H_{1,2}\right)\left(k_{1,2}-1\right)>0 \\
m-H_{0,1}^{\prime}\left(k_{0,1}-1\right)-\left(h_{1}+H_{1,2}^{\prime}\right)\left(k_{1,2}-1\right)-\left(h_{2}+H_{2,3}\right)\left(k_{2,3}-1\right)>0 \\
\left\{\begin{array}{l}
m-H_{0,1}^{\prime}\left(k_{0,1}-1\right)-\left(h_{1}+H_{1,2}\right)\left(k_{1,2}-1\right)>0,(n=1) \\
m-H_{0,1}^{\prime}\left(k_{0,1}-1\right)-\left(h_{n}+H_{n, n+1}\right)\left(k_{n . n+1}-1\right)-\sum_{i}^{n-1}\left(h_{i}+H_{i, i+1}^{\prime}\right)\left(k_{i, i+1}-1\right)>0,(n>1)
\end{array}\right.
\end{gathered}
$$

Let

$$
\left\{\begin{array}{l}
m-H_{0,1}^{\prime}\left(k_{0,1}-1\right)-\left(h_{1}+H_{1,2}\right)\left(k_{1,2}-1\right)=0,(n=1) \\
m-H_{0,1}^{\prime}\left(k_{0,1}-1\right)-\left(h_{n}+H_{n, n+1}\right)\left(k_{n . n+1}-1\right)-\sum_{i}^{n-1}\left(h_{i}+H_{i, i+1}^{\prime}\right)\left(k_{i, i+1}-1\right)=0,(n>1)
\end{array}\right.
$$

Then

$$
H_{n, n+1}=\left\{\begin{array}{l}
\frac{m-H_{0,1}^{\prime}\left(k_{0,1}-1\right)}{\left(k_{1,2}-1\right)}-h_{1},(n=1) \\
\frac{m-H_{0,1}^{\prime}\left(k_{0,1}-1\right)-\sum_{i}^{n-1}\left(h_{i}+H_{i, i+1}^{\prime}\right)\left(k_{i, i+1}-1\right)}{\left(k_{n, n+1}-1\right)}-h_{n}(n>1)
\end{array}\right.
$$

$H_{n, n+1}$ in the formula above is defined as the height of linkage (HoL) between KS. Below are several explanations of this concept:

(1) To be specific, the HoL, as a height difference limit, represents the spatial relationship that allows for fracturing of the lower KS to cause fracturing the upper one.

(2) After KS $n$ fractures, KS $n+1$ above it tends to fracture if its vertical distance to KS $n$ is smaller than the corresponding HoL (Figure 8a). If the strata between them are sufficiently thick and able to withstand relatively large deformation, fracturing of KS $n$ will not result in fracturing of KS $n+1$ (Figure 8b).

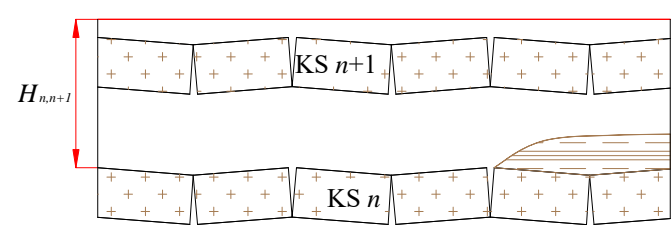

(a)

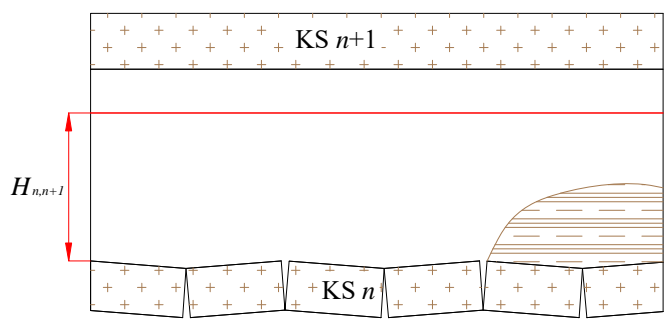

(b)

Figure 8. HoL between KS: (a) Height difference < HoL; (b) Height difference > HoL.

The analysis above, when combined with Formula (7), suggests that the linkage between two adjacent KS allows for fracturing of a lower KS to cause fracturing of the adjacent KS above it as along as their relative locations satisfy the spatial relationship required. As a result, the mining-induced fractures will pass through the upper KS, thereby increasing the height of CFZ in overburden.

Table 2 shows the relationship between the HoL between KS and the CFZ's height. If the adjacent KS satisfy different spatial relationship, the state of KS and the height of CFZ will be different under the influence of mining. 
Table 2. Models explaining the relationship between the HoL between KS and the CFZ's height.

\begin{tabular}{|c|c|c|c|c|}
\hline Model Type & Model a & Model b & Model c & Model d \\
\hline Illustration & 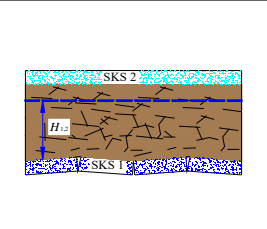 & 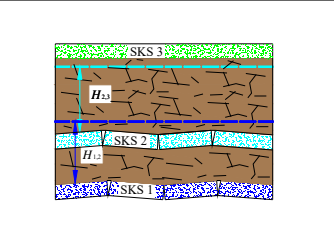 & 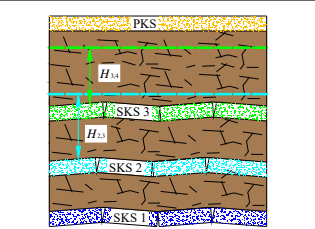 & 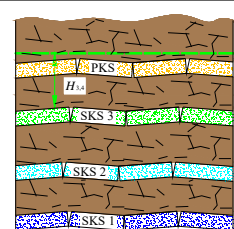 \\
\hline $\begin{array}{l}\text { Spatial relationships } \\
\text { between adjacent KS }\end{array}$ & $\begin{array}{l}\text { The height difference } \\
\text { between SKS } 2 \text { and } \\
\text { SKS } 1 \text { is greater than } \\
\text { the HoL between them. }\end{array}$ & $\begin{array}{l}\text { The height difference } \\
\text { between SKS } 2 \text { and SKS } 1 \text { is } \\
\text { smaller than the HoL } \\
\text { between them, while the } \\
\text { height difference between } \\
\text { SKS } 3 \text { and SKS } 2 \text { is greater } \\
\text { than the corresponding HoL. }\end{array}$ & $\begin{array}{l}\text { The height difference } \\
\text { between SKS } 3 \text { and SKS } 2 \\
\text { is smaller than the HoL } \\
\text { between them, while the } \\
\text { height difference between } \\
\text { PKS and SKS } 3 \text { exceeds the } \\
\text { corresponding HoL. }\end{array}$ & $\begin{array}{l}\text { The height } \\
\text { difference between } \\
\text { PKS and SKS } 3 \text { is } \\
\text { less than the HoL } \\
\text { between them. }\end{array}$ \\
\hline State of KS & SKS 2 is unfractured. & $\begin{array}{l}\text { SKS } 2 \text { is fractured while SKS } \\
3 \text { is unfractured }\end{array}$ & $\begin{array}{l}\text { SKS } 3 \text { is fractured while } \\
\text { PKS is unfractured }\end{array}$ & PKS is fractured \\
\hline The height of CFZ & $\begin{array}{l}\text { Fractures terminate at } \\
\text { the bottom of SKS } 2 \text {. }\end{array}$ & $\begin{array}{l}\text { Fractures propagate through } \\
\text { SKS } 2 \text { and terminate at the } \\
\text { bottom of SKS } 3 \text {. }\end{array}$ & $\begin{array}{l}\text { Fractures run through SKS } \\
3 \text { and terminate at the } \\
\text { bottom of PKS. }\end{array}$ & $\begin{array}{l}\text { Fractures extend } \\
\text { through all key } \\
\text { strata and reach the } \\
\text { surface }\end{array}$ \\
\hline
\end{tabular}

\section{Discussion}

The vertical distance from SKS 1 to the coal seam at working face 20104 is $10.21 \mathrm{~m}$. Before SKS 1 fractured, the immediate roof below it caved in to the goaf. The bulking factors of caved rocks in goaf normally fall within the range of 1.1 to 1.30 . For a bulking factor of 1.30 and mining height of $6.2 \mathrm{~m}$, the height of the free space below SKS 1 was $\Delta=3.14 \mathrm{~m}$. It is clear that this space was large enough to allow for SKS 1 to fracture and fall as the face advanced (Figure 6).

The HoL analysis reveals that for given geological conditions (relative locations of KS) and mining height, the HoL between KS depends on the bulking factors of the strata in the fractured zone. According to the field measurements from working face 20104, the strata within the fractured zone did not cave in and its behavior was characterized by fracturing, bed separation and displacements parallel to bed planes. This enables the strata in this zone to retain the original layered structure. It is reasonable to infer that the strata within the fractured zone did not increase in volume significantly and their bulking factors should be much lower than those of strata in the caved zone. In the vertical direction, the bulking factor of a stratum in the fractured zone tends to decrease logarithmically with the distance from the coal seam. Equation (8) describes the relationship between the bulking factor of the strata within the fractured zone measured at Yangquan No.1 mine and the vertical distance to the mining coal seam [27], and the graph of the equation is shown as Figure 9.

$$
K=1.083-0.017 \cdot \ln (h) \quad h<100 \mathrm{~m}
$$

where $K$ is the bulking factor of the strata within the fractured zone and $h$ is the vertical distance to the mining coal seam.

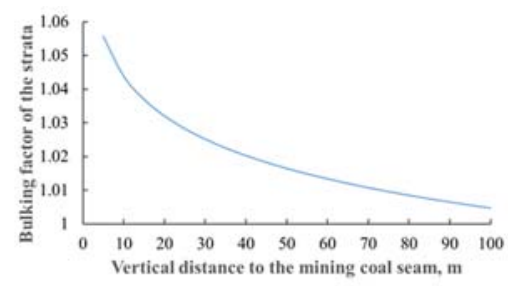

Figure 9. Bulking factor of the strata within the fractured zone. 
The bulking factors of strata at the Wangjialing coal mine were calculated using Equation (8), due to a lack of field measurements and experimental data. The HoL values that were estimated from the bulking factors obtained are presented in Table 3. Even though the estimated HoL between KS can not reflect the real conditions at working face 20104, it can be used to explain the abnormal height of local CFZ as follows:

(1) The actual height difference between SKS 1 and SKS 2 was $52.95 \mathrm{~m}$, smaller than the HoL between them, at $61.25 \mathrm{~m}$. This suggests that the fracturing of SKS 1 can cause SKS 2 to fracture and thereby lead to continuous upward growth of fractures in the overburden, as demonstrated by model $\mathrm{b}$ in Table 2.

(2) The actual height difference between SKS 2 and SKS 3 was $78.55 \mathrm{~m}$, greater than the HoL between them, at $59.32 \mathrm{~m}$. So the fracturing of SKS 2 did not cause damage to SKS 3 and the fractures terminated at the bottom of SKS 3, as demonstrated by model $b$ in Table 2.

(3) The estimated HoL between KS indicates that decreasing the mining height or backfilling the goaf can prevent SKS 1 from fracturing or ensure the height difference between SKS 2 and SKS 1 exceeds corresponding HoL (model a in Table 2), thereby substantially reducing the CFZ's height. Conversely, if the vertical distance between SKS 3 and SKS 2 is smaller than the HoL between them, then the fractures in overburden can propagate through SKS 3 and continuously growing upward (model c in Table 2), thus leading to an upward expansion of the CFZ. Some conductive fractures may even reach the surface (model $d$ in Table 2).

Table 3. HoL between adjacent KS at working face 20104.

\begin{tabular}{ccc}
\hline Adjacent KS & Height Difference between Them $(\mathbf{m})$ & HoL between Them $(\mathbf{m})$ \\
\hline SKS 1-SKS 2 & 52.95 & 61.25 \\
SKS 2-SKS 3 & 78.55 & 59.32 \\
\hline
\end{tabular}

Model $b$ suggests that the top of the CFZ at working face 20104 should be located near the bottom of SKS 3, and its vertical distance to the coal seam should be $141.71 \mathrm{~m}$, which is close to the measured height of the CFZ (148 m). It is worth mentioning that the HoL is an explanatory model for illustrating the abnormal increase in the height of CFZ and the CFZ's height predicted by it this model is roughly consistent with the field measurements. As there are relatively few studies of the bulking factors of rocks in the fractured zone, more field measurements and case studies should be conducted to verify the validity of the model proposed.

\section{Conclusions}

This study analyzed the spatial relationships between KS required for their fracturing. The height of linkage between KS was introduced and was used in combination with field measurements to explain the abnormal height of the CFZ at working face 20104, Wangialing coal mine. The main conclusions of the study are as follows:

(1) The measured height of the CFZ at working face 20104 is significantly different from the prediction by an empirical formula. The mining induced fractures in the overburden ultimately terminated near the bottom of SKS 3. The measured height of the CFZ was $148 \mathrm{~m}$, about 23.87 times greater than the mining height. This zone can be divided into two zones: a $23.96 \mathrm{~m}$ high caved zone (3.86 times the mining height) and a $124.04 \mathrm{~m}$ high fractured zone (20.01 times the mining height). The measured heights of the CFZ were 1.98 to 2.61 times greater than the predictions from an empirical formula.

(2) There are linkage effects between adjacent KS during mining. The height difference between two adjacent KS, KS $n$ and $K S n+1$, should be smaller than the HoL between them in order to allow for the fracturing of KS $n$ to cause fracturing of KS $n+1$. Otherwise, $\mathrm{KS} n+1$ will not fail after the fracturing of KS $n$. The linkage between adjacent KS will cause fracturing of a high KS and allow for 
fractures to run through the high KS as well as the strata controlled by it, thus leading to an abnormal increase in the height of CFZ in overburden.

(3) The explanatory model for the CFZ's height indicates that the conductive fractures in the overburden would stop growth at a location near the bottom of SKS 3 and the corresponding height of the CFZ should be $141.71 \mathrm{~m}$, a slight decrease of $6.29 \mathrm{~m}$ from the measured height, at $148 \mathrm{~m}$. This consistency demonstrates that the model is capable of explaining the height of the CFZ induced by thick seam mining at the Wangjialing coal mine.

Acknowledgments: We acknowledge the financial support for this work, provided by the National Natural Science Foundation of China (Grant No. 51474206, No. 51404254), the Fundamental Research Funds for the Central Universities (2014QNA49), the National Basic Research Program of China (973 Program-No. 2015CB162500).

Author Contributions: All the authors contributed to publishing this paper. Peng Li prepared and edited the manuscript. Xufeng Wang and Wenhao Cao participated in the data processing during the research process. Dong-sheng Zhang revised and reviewed the manuscript. Dongdong Qin and Hongzhi Wang partially participated in the literature research and technological development.

Conflicts of Interest: The authors declare no conflict of interest.

\section{Abbreviations}

$\begin{array}{ll}\text { CFZ } & \text { Conductive Fracture Zone } \\ \text { KS } & \text { Key Strata } \\ \text { HoL } & \text { Height of Linkage } \\ \text { PKS } & \text { Primary Key Stratum } \\ \text { SKS } & \text { Secondary Key Strata }\end{array}$

\section{References}

1. Wang, W.X.; Sui, W.H.; Faybishenko, B.; Stringfellow, W.T. Permeability variations within mining-induced fractured rockmass and its influence on groundwater inrush. Environ. Earth Sci. 2016, 75, 326. [CrossRef]

2. Wang, S.F.; Li, X.B.; Wang, D.M. Mining-induced void distribution and application in the hydro-thermal investigation and control of an underground coal fire: A case study. Process Saf. Environ. Prot. 2016, 102, 734-756. [CrossRef]

3. Qu, Q.D.; Xu, J.L.; Wu, R.L.; Qin, W.; Hu, G.Z. Three-zone characterisation of coupled strata and gas behaviour in multi-seam mining. Int. J. Rock Mech. Min. Sci. 2015, 78, 91-98. [CrossRef]

4. Qiao, W.; Li, W.P.; Li, T.; Chang, J.Y.; Wang, Q.Q. Effects of coal mining on shallow water resources in semiarid regions: A case study in the Shennan mining area, Shaanxi, China. Mine Water Environ. 2017, 36, 104-113. [CrossRef]

5. Zhang, D.S.; Fan, G.W.; Liu, Y.D.; Ma, L.Q. Field trials of aquifer protection in longwall mining of shallow coal seams in China. Int. J. Rock Mech. Min. Sci. 2010, 47, 908-914. [CrossRef]

6. Zhang, D.S.; Fan, G.W.; Ma, L.Q.; Wang, X.F. Aquifer protection during longwall mining of shallow coal seams: A case study in the Shendong Coalfield of China. Int. J. Coal Geol. 2011, 86, 190-196. [CrossRef]

7. Ju, J.F.; $\mathrm{Xu}$, J.L. Surface stepped subsidence related to top-coal caving longwall mining of extremely thick coalseam under shallow cover. Int. J. Rock Mech. Min. Sci. 2015, 78, 27-35.

8. Shi, L.; Liu, Y.F.; Wang, S.D. Overburden failure height and fissure evolution characteristics of deep buried, extra thick coal seam and fully-mechanized caving mining of China. In Proceedings of the 2015 International Conference on Water Resources and Environment, Beijing, China, 25-28 July 2015; pp. 207-216.

9. Wang, F.T.; TU, S.H.; Zhang, C.; Zhang, Y.W. Evolution mechanism of water-flowing zones and control technology for longwall mining in shallow coal seams beneath gully topography. Environ. Earth Sci. 2016, 75, 1309. [CrossRef]

10. Wang, X.F.; Zhang, D.S.; Zhang, C.G.; Fan, G.W. Mechanism of Mining-induced Slope Movement for Gullies Overlaying Shallow Coal Seams. J. Mt. Sci. 2013, 10, 388-397. [CrossRef]

11. Zhang, J.; Jiang, H.; Deng, X.; Ju, F. Prediction of the height of the water-conducting zone above the mined panel in solid backfill mining. Mine Water Environ. 2014, 33, 317-326. [CrossRef] 
12. Palchik, V. Influence of physical characteristics of weak rock mass on height of caved zone over abandoned subsurface coal mines. Environ. Geol. 2002, 42, 92-101. [CrossRef]

13. Palchik, V. Formation of fractured zones in overburden due to longwall mining. Environ. Geol. 2003, 44, 28-38.

14. Palchik, V. Bulking factors and extents of caved zones in weathered overburden of shallow abandoned underground workings. Int. J. Mech. Min. Sci. 2015, 79, 227-240. [CrossRef]

15. Cheng, G.W.; Ma, T.H.; Tang, C.; Liu, H.Y.; Wang, S.J. Zoning model for coal mining-induced strata movement based on microseismic monitoring. Int. J. Rock Mech. Min. Sci. 2017, 94, 123-138. [CrossRef]

16. Xiong, Z.Q.; Wang, C.; Zhang, N.C. A Field Investigation for overlying strata behaviour study during protective seam longwall overmining. Arab. J. Geosci. 2015, 8, 7797-7809. [CrossRef]

17. Wang, H.Z.; Zhang, D.S.; Wang, X.F.; Zhang, W. Visual exploration of the spatiotemporal evolution law of overburden failure and mining-induced fractures: A case study of the Wangjialing coal mine in China. Minerals 2017, 7, 35. [CrossRef]

18. Niedbalski, Z.; Malkowski, P.; Majcherczyk, T. Monitoring of stand-and-roof-bolting support: Desing optimization. Acta Geodyn. Geomater. 2013, 10, 215-226. [CrossRef]

19. Malkowski, P. The impact of the physical model selection and rock mass stratification on the results of numerical calculations of the state of rock mass deformation around the roadways. Tunn. Undergr. Space Technol. 2015, 50, 365-375. [CrossRef]

20. Majcherczyk, T.; Malkowski, P.; Niedbalski, Z. Describing quality of rocks around underground headings: Endoscopic observations of fractures. In Proceedings of the International Symposium of the International-Society-for-Rock-Mechanics, Brno, Czech Republic, 18 May-20 August 2005; pp. 355-360.

21. Zhang, W.; Zhang, D.S.; Ma, L.Q. Dynamic evolution characteristics of mining-induced fractures in overlying strata detected by radon. Nuclear Sci. Tech. 2011, 22, 334-337.

22. Zhang, W.; Zhang, D.S.; Wu, L.X.; Wang, H.Z. On-site radon detection of mining-induced fractures from overlying strata to the surface: A case study of the Baoshan coal mine in China. Energies 2014, 7, 8483-8507. [CrossRef]

23. Xu, J.L.; Wang, X.Z.; Liu, W.T.; Wang, Z.G. Effects of primary key stratum location on height of water flowing fracture zone. Chin. J. Rock Mech. Eng. 2009, 28, 380-385. (In Chinese)

24. Miao, X.X.; Cui, X.M.; Wang, J.A.; Xu, J.L. The height of fractured water-conducting zone in undermined rock strata. Eng. Geol. 2011, 120, 32-39. [CrossRef]

25. Xu, J.L.; Qian, M.G. Method to distinguish key strata in overburden. J. China Univ. Min. Technol. 2000, 29, 463-467.

26. Ju, J.L.; Xu, J.L.; Xu, J.M. A case study of surface borehole wall dislocation induced by top-coal longwall mining. Energies 2017, 10, 2100. [CrossRef]

27. Shao, H.; Jiang, S.G.; Wang, L.Y.; Wu, Z.Y. Bulking factor of the strata overlying the gob and a threedimensional numerical simulation of the air leakage flow field. Min. Sci. Technol. 2011, 21, 261-266. 